\title{
EL LENGUAJE COMO DISCRIMINACIÓN
}

\author{
Álvaro García Vargas \\ garcia.alvaro67@gmail.com \\ Universidad de Arte y Ciencias Sociales ARCIS \\ Chile.
}

\section{Resumen}

El presente trabajo es una reflexión en torno a la discriminación que ejercemos a través del lenguaje en diversas culturas. Muchas veces no nos percatarnos de aquello pues muchos de estos hechos lingüísticos nos parecen normales debido a, entre otras cosas, la aceptación de las reglas gramaticales. Se hace referencia a las diferencias de uso de palabras que usamos diariamente y sus connotaciones, y se entregan sugerencias a fin de cambiar el uso de ciertas estructuras para hacerlo más inclusivo. Por último, se invita a reflexionar sobre la posibilidad de un cambio de actitud para terminar con dichas expresiones.

Palabras claves: lenguaje - discriminación - género - educación

\section{Abstract}

This paper is a reflection about the discrimination we exert through language in different cultures. Most of the time, we do not realise of that situation because many of these linguistic facts seem to be normal for us due to, among many other reasons, the acceptance of the grammar rules. There are some references to the differences of usage of daily words and their connotations, and some suggestions are given in order to change the usage of certain structures to make language more inclusive. Finally, there is an invitation to think over the possibility of change of attitude to finish with such expressions.

Key words: language - discrimination - gender - education 


\section{Introducción}

Podríamos decir, para empezar, que el lenguaje es lo que nos hace ser personas y habitar lo espacios que nos rodean, lo que significa interactuar con otros y otras al mismo tiempo. Podemos vernos en ellas y ellos reflejados en nosotros y en nuestra forma de comunicarnos. Somos parte de una misma comunidad lingüística, con sus errores y virtudes.

Desde hace un tiempo ha circulado un correo electrónico en la red con una lista de palabras que muestran el uso que hacemos de los vocablos mujer y hombre en nuestra sociedad. Cito algunos ejemplos de dichos usos, más las definiciones tomadas del sitio [en línea] http://www.rae.es [consulta: 2 de julio 2010]

Bicho: 1. Animal.

Bicha: 4. Arq. Figura fantástica, en forma de mujer de medio cuerpo arriba y de pez u otro animal en la parte inferior, que entre frutas y follajes se emplea como objeto de ornamentación. 5. Despectivo coloquial en El Salvador y Honduras. Niña, muchacha 6. Coloquial en El Salvador. Novia. (Mujer que mantiene relaciones amorosas)

Cualquier: 1. Adjetivo indefinido. Cualquiera.

Cualquiera: 2. Mujer de mala vida.

Golfo: 1. Gran porción de mar que se interna en la tierra entre dos cabos.

Golfa: 3. Prostituta.

Hombrezuelo: Diminutivo de hombre (como es regular, no está en el Diccionario de la Real Academia Española)

Mujerzuela: 1. Mujer de poca estimación. 2 Mujer perdida, de mala vida. 
Álvaro García Vargas. El lenguaje como discriminación.

Hombre público: El que tiene presencia e influjo en la vida social

Mujer pública: Prostituta

Lobo: 6. en Perú. Astuto, agudo.

Loba: 3. en Uruguay. Mujer sensualmente atractiva.

Perdido: 1. Que no tiene o no lleva destino determinado.

Perdida: 5. Prostituta. (Si bajan verán la entrada mujer pública cuya primera entrada es prostituta).

Mujer perdida. 1 Prostituta.

Perro: 1. Mamífero doméstico de la familia de los cánidos.

Perra: 2. Prostituta.

Puto: 3. Necio. 4. Hombre que tiene concúbito (coito) con persona de su sexo.

Puta: 1 Prostituta.

Zorro: 5. Hombre muy taimado y astuto.

Zorra: 4. Prostituta.

Otro ejemplo, en la misma línea, aparecido en la prensa peruana, nos muestra a un congresista, el parlamentario peruano Carlos Torres Caro, señalando: "El hombre público es como la mujer pública: todo el mundo tiene derecho a meterle la mano"1

Otras expresiones no son tan abiertas en su significado, pero tienen una connotación negativa como las siguientes: araña viuda negra, definida como animal elegante y de hábitos nocturnos, la hembra puede devorar al macho en el apareamiento, lo que da el nombre a la especie; otro 
ejemplo es el nombre que se les da a los huracanes en los EE.UU., el género de la primera tormenta del año alterna cada año, así la primera tormenta de un año impar recibe nombre femenino, mientras que la primera de un año par, masculino. Socialmente el número par es visto por muchos como lo normal, lo simétrico mientras lo impar como lo asimétrico. La lista es muy larga para citarla aquí, pero, estos ejemplos nos pueden ayudar a entender mejor que hay muchísimas expresiones que pasan desapercibidas y de las cuales nos apropiamos sin leer ni entender ni percibir el sentido profundo, la estructura profunda que subyace a semejantes expresiones, siguiendo a Chomsky.

El Ministerio del Trabajo y Asuntos Sociales de España encargó a mediados de los años 90 una revisión de los usos de ciertas palabras y expresiones de la lengua castellana a través de su Comisión Consultora del Lenguaje. Algunas de la conclusiones de esta Comisión son bastante de sentido común, nada complejas, como usar la versión femenina cuando se pueda, como en los siguientes ejemplos: la clienta, la peona, la ayudanta, la cancillera, la oficiala, la parienta, la edila o la alcaldesa, la concejala, la fiscala, la jueza, la diputada, la senadora y, como lo hacíamos en Chile hasta el 11 de marzo, la presidenta. Hay un sinnúmero de sugerencias que se entregan y que sería largo enumerar, algunas de las cuales dejaré para la conclusión. Para muestra, sólo un botón del trabajo de esta Comisión en el campo de la educación, citaré una última ilustración, es una oración tomada de la normativa que rige el acceso a la universidad en España: "Los criterios específicos de corrección deberán ser conocidos por los miembros de los tribunales en el momento de realizarse las pruebas". Entre las alternativas que se sugieren a la expresión "los miembros" la Comisión nos entrega las siguientes: cada miembro; las y los miembros; los y las miembros. Asimismo, no se pueden dejar de lado algunos usos nuevos, como el que hacen algunas mujeres que son partidarias de convertir el sustantivo común miembro en sustantivo de doble forma, es decir, masculino y femenino, invitando a usar la palabra miembra, es decir, en esta misma oración escribir "Los criterios específicos de corrección deberán ser conocidos por las miembras y los miembros y/o miembros y miembras de los tribunales en el momento de realizarse la pruebas". También figura como sugerencia la palabra membresía, palabra muy frecuente en documentos latinoamericanos, pero todavía poco usada en España o la dirigencia, para hablar de dirigentes de 
ambos sexos, la defensoría en el caso de abogados y abogadas.

Mi interés por esta tema nace de mi convicción y mi propia lectura del lenguaje como una herramienta no sólo para comunicarnos sino del lenguaje visto como biopolítica, una herramienta de poder, que nos controla, nos ata a nuestras culturas, y a quienes manejan nuestros discursos a través de la academia, la literatura, la música, el arte, los medios de comunicación, el marketing, los sistemas económicos, las religiones, los sistemas tecnológicos actuales, el sistema educativo y un largo etc.

\section{El control social del lenguaje en la educación.}

La primera puerta que nos abren y cruzamos para entrar en nuestras sociedades es la escuela. Aun cuando muchos estudios señalan que no es así, la imagen que tenemos de la educación es el de una institución neutral. Sin embargo, los lingüistas Gumperz y Bennet señalan que en el desarrollo de los programas escolares, algunos miembros de las minorías quedarían rezagados pues "muestran igualmente los más bajos índices de inteligencia, según los tests, (ver resultados SIMCE 2009, para mayor abundamiento) y muestran una alta tasa de población desescolarizada, lo que da como resultado que no sean aceptados en aquellos puestos de trabajo que requieren una determinada titulación escolar" (Gumperz, J. J. y Bennett, A. 1981, p. 128), en el caso de Chile, muchas y muchos quedan descartados para entrar al sistema universitario público y deben optar, en algunos casos, al sistema educativo privado. Si bien podemos caer fácilmente en generalizaciones, podemos sustentar nuestras opiniones basándonos en los recientes resultados del SIMCE. Éstos nos muestran donde están los mejores resultados y los peores en nuestra sociedad. ¿Es esto producto del azar? No es difícil darse cuenta que tanto niñas como niños que tienen padres y madres con un alto nivel de escolarización, ambos profesionales en algunos casos, con mayores recursos económicos para proveerles los materiales que se requieren en una educación de alto nivel, tendrán un resultado académico más alto que aquellos niños y niñas que no tienen ni padres ni madres profesionales, ni siquiera un miembro o miembra de su familia profesional, que tampoco están expuestos a un uso más elaborado del lenguaje, con escasos 
recursos materiales para enfrentar los desafíos escolares, etc. Veamos que nos dice el resultado SIMCE 2009 a través de la Tabla 5, que muestra las Características de los Grupos Socioeconómicos de $4^{0}$ Básico. [en línea] (Metodología de Construcción de grupos Socioeconómicos en SIMCE 2009 4ํㅡㄹásico 2009. SIMCE. Ministerio de Educación. Junio 2010) [consulta: 2 julio de 2010]

\begin{tabular}{|c|c|c|c|c|c|}
\hline \multicolumn{2}{|c|}{ Grupo socioeconómico } & $\begin{array}{l}\text { Promedio de } \\
\text { años de } \\
\text { escolaridad de } \\
\text { la madre }\end{array}$ & $\begin{array}{l}\text { Promedio de } \\
\text { años de } \\
\text { escolaridad del } \\
\text { padre }\end{array}$ & $\begin{array}{l}\text { Ingreso } \\
\text { promedio del } \\
\text { hogar }\end{array}$ & $\begin{array}{l}\text { IVE- } \\
\text { SINAE }\end{array}$ \\
\hline \multirow{2}{*}{$\begin{array}{l}\text { Bajo } \\
\text { (A) }\end{array}$} & Promedio & 8 & 7 & 130.098 & 86 \\
\hline & $\begin{array}{l}\text { Desviació } \\
\mathrm{n} \\
\text { Estándar }\end{array}$ & 1 & 1 & 53.439 & 11 \\
\hline \multirow{2}{*}{$\begin{array}{l}\text { Medio } \\
\text { Bajo (B) }\end{array}$} & Promedio & 10 & 10 & 190.733 & 64 \\
\hline & Desv. Est. & 1 & 1 & 53.259 & 10 \\
\hline \multirow[t]{2}{*}{ Medio $(\mathrm{C})$} & Promedio & 12 & 12 & 300.795 & 37 \\
\hline & Desv. Est. & 1 & 1 & 207.630 & 10 \\
\hline \multirow{2}{*}{$\begin{array}{l}\text { Medio } \\
\text { Alto (B) }\end{array}$} & Promedio & 14 & 14 & 657.658 & 16 \\
\hline & Desv. Est. & 1 & 1 & 207.630 & 7 \\
\hline \multirow[t]{2}{*}{ Alto $(A)$} & Promedio & 16 & 17 & 1.734 .865 & 0 \\
\hline & Desv. Est, & 1 & 1 & 320.138 & 1 \\
\hline
\end{tabular}

La siguiente Tabla, a su vez, muestra la mismas características con $8^{\circ}$ Básico [en línea] (Metodología de Construcción de grupos Socioeconómicos en SIMCE 2009 8 Básico 2009. SIMCE. Ministerio de Educación. Junio 2010) [consulta: 2 julio de 2010] 


\begin{tabular}{|c|c|c|c|c|c|}
\hline \multicolumn{2}{|c|}{ Grupo socioeconómico } & $\begin{array}{l}\text { Promedio de } \\
\text { años de } \\
\text { escolaridad de } \\
\text { la madre }\end{array}$ & $\begin{array}{l}\text { Promedio de } \\
\text { años de } \\
\text { escolaridad del } \\
\text { padre }\end{array}$ & $\begin{array}{l}\text { Ingreso } \\
\text { promedio del } \\
\text { hogar }\end{array}$ & $\begin{array}{l}\text { IVE- } \\
\text { SINAE }\end{array}$ \\
\hline \multirow{2}{*}{$\begin{array}{l}\text { Bajo } \\
\text { (A) }\end{array}$} & Promedio & 7 & 7 & 140.889 & 79 \\
\hline & $\begin{array}{l}\text { Desviació } \\
\mathrm{n} \\
\text { Estándar }\end{array}$ & 1 & 1 & 50.315 & 10 \\
\hline \multirow{2}{*}{$\begin{array}{l}\text { Medio } \\
\text { Bajo (B) }\end{array}$} & Promedio & 9 & 9 & 200.881 & 61 \\
\hline & Desv. Est. & 1 & 1 & 48.531 & 9 \\
\hline \multirow[t]{2}{*}{ Medio $(\mathrm{C})$} & Promedio & 11 & 11 & 316.147 & 37 \\
\hline & Desv. Est. & 1 & 1 & 207.630 & 9 \\
\hline \multirow{2}{*}{$\begin{array}{l}\text { Medio } \\
\text { Alto (B) }\end{array}$} & Promedio & 14 & 14 & 631.293 & 17 \\
\hline & Desv. Est. & 1 & 1 & 191.868 & 8 \\
\hline \multirow[t]{2}{*}{ Alto $(A)$} & Promedio & 16 & 17 & 1.668 .108 & 1 \\
\hline & Desv. Est. & 1 & 1 & 333.298 & 2 \\
\hline
\end{tabular}

Señala Basil Berstein, sociólogo y lingüista británico, "las relaciones sociales regulan los significados que creamos y se asignan a través de roles constituidos por estas relaciones sociales, y estos significados actúan selectivamente sobre las opciones léxicas y sintácticas, la metáfora y el simbolismo. Entre el lenguaje y el habla está la estructura social" (Berstein 2001, p. 101), es decir, la división del trabajo tiene un directa relación con el uso del lenguaje, y como en el caso citado anteriormente, en los resultados de los alumnos en pruebas de medición de conocimientos. Preocupado por el fracaso escolar de las clases trabajadoras, sus investigaciones dan prueba de que la escuela desempeña un papel importante en la reproducción de las desigualdades de raza, género, clases social, región y religión. Define en profundidad los conceptos de "código elaborado y restringido". "En la medida en que el lenguaje da poder a un grupo particular, dicho grupo debe intentar mantener el control sobre su propio lenguaje, dialecto o estilo estableciendo patrones de 
"buena" habla e impidiendo el acceso a los mismos a los restantes grupos" (Gumperz, J. J. y Bennett, A. 1981, p. 131). Desde esta perspectiva, podemos entender más claramente los resultados del SIMCE como los resultados que una sociedad discriminadora solamente puede generar, discriminación a través de medios tangibles e intangibles, intangibles como el lenguaje, en este caso, el acceso al lenguaje dominante en la educación está garantizado para aquellos que tienen contacto con el uso de un código más elaborado de manera habitual. Lamentablemente, los programas que se han realizado para equiparar la educación a veces no dan los resultados esperados, "de hecho tales programas tienden a veces a perpetuar los mismos problemas que intentan curar, contribuyendo por tanto, de manera indirecta, al mantenimiento de una situación de desigualdad social" (Gumperz, J. J. y Bennett, A. 1981, p. 129). Un ejemplo cercano pero bastante desconocido. Hoy una de las nuevas brechas que se agregan es la tecnológica, ¿cómo poder implementar redes tecnológicas al alcance de los alumnos y sus familias?. Por cierto la escuela es un lugar donde aquello puede ocurrir. Muchos de alumnos y alumnas no tienen un computador en casa, muchos de los que sí tienen no tienen acceso asegurado a Internet, "en Chile el promedio nacional de alumnos por computador ha evolucionado drásticamente desde el año 2000 (70 alumnos por computador), en el año 2010 se estima que alcanzará a un promedio de 10 alumnos por computador"2. Lamentablemente, Chile es uno de los países con mayor costo de acceso a internet, aun cuando la CEPAL ha propuesto que la banda ancha sea considerada como un bien público global, con acceso para todos, aunque no necesariamente gratuito, para permitir el acceso a todo el mundo. En la actualidad, las empresas proveedoras de banda ancha en Chile deben pagar entre 40 y 50 dólares por megabyte a las compañías dueñas de los cables de fibra óptica submarina que transmiten el tráfico entre Chile y Estados Unidos. Los países de la Organización de Cooperación para el Desarrollo Económico (OCDE, organización de la cual Chile es miembro) pagan en promedio entre 8 y 10 dólares por el mismo servicio. Pues bien, algunos profesores/as han señalado que la red Enlaces implementada en algunas escuelas ha sido un fracaso, pues los computadores no tenían las capacidades técnicas para enfrentar los nuevos programas que son más veloces y cada día más complejos, además muchos de los programas requeridos son pagados, etc. Algunos profesores/as, militantes del software libre, han estado instalando sistemas 
operativos LINUX, de descarga gratuita, como Ubuntu, para poder recuperar los computadores y mejorar el acceso de sus estudiantes a internet. Por otra parte, muchos sostenedores no gastan dinero en tener salas de computación bien equipadas para sus alumnos/as, y para que las escuelas de escasos recursos puedan tener banda ancha hay que postular a proyectos de la red Enlaces del MINEDUC. Es decir, los programas para mejorar el acceso y la calidad a la educación a veces son muy burocráticos y engorrosos. Por último, ¿cómo pueden saber los padres que el colegio en el que están sus hijas/os postula a los proyectos en cuestión? Muchas veces los colegios se venden a través de fotografías y dípticos muy alejados de la realidad. Como reza el presente Coloquio, otros tipos de discriminación, en este caso aquella que dice relación con el control del lenguaje tecnológico.

Otra forma de discriminación, señalada por los mismos lingüistas ya citados anteriormente, hace referencia, por ejemplo, al desdén hacia el acento de ciertas comunidades dentro de una cultura dominante, por ejemplo, el acento de los afroamericanos en Estados Unidos, considerado menos complejo, cuando, como se señala en lingüística, ningún dialecto es menos complejo que otro. También se hace referencia al acceso que tenían del conocimiento del sánscrito en India las personas nacidas en las más importantes castas bhramins, pero no así quienes eran miembros de las castas más bajas; se cita el uso del RP en el inglés (el acento hablado en Oxford, en Cambridge y en general en las universidades del Reino Unido, por los miembros de la nobleza, la clase alta, los medios de comunicación); se hace referencia al caso de la China imperial con su distribución piramidal de la lengua, donde el uso del mandarín era requisito para obtener un puesto en la administración del estado, dialecto usado en la literatura, en los documentos oficiales y en la escritura en general, mientras que a medida que se bajaba en la escala iba en aumento el número de dialectos, muchos de los cuales son ininteligibles entre ellos. Este caso nos dice mucho y se parece a los actuales problemas educativos en materia lingüística. En China la mayor parte de las personas de las áreas rurales empleaban y aun emplean lenguas muy distintas del mandarín, por lo tanto debían aprender a manejarlo fluidamente, conjuntamente con sus reglas culturales, de etiqueta y de caligrafía. Esto tomaba bastantes años, y requería costearse un tutor que les proporcionara una educación adecuada, lo que debía ser pagado, "dejando el acceso a los puestos 
de poder a los miembros de la minoría adinerada" (Gumperz, J. J. y Bennett, A. 1981, p. 131). ¿Suena parecido a nuestra realidad? Si se hubiera realizado una prueba algo parecida al SIMCE es muy probable que los resultados serían parecidos a los de nuestros alumnos y alumnas.

La existencia de la diferencia de estilos, por ejemplo, en nuestro español de Chile, puede llegar a convertirse en "vehículo de transmisión y mantenimiento de los estereotipos sociales" (Gumperz, J. J. y Bennett, A. 1981, p. 133). Es decir, más que un tema lingüístico, puesto que no existen códigos, lenguas, ni estilos inferiores, es un tema de actitud hacia el uso de determinados dialectos 0 estilos de habla, como la pronunciación en Chile de las letras $\underline{\mathrm{c}}$ y $\underline{h}$, antiguamente llamada che. Ésta tiene tres pronunciaciones reconocidas /tt $/ / \mathrm{t} / /$ y $/ \mathrm{g} /$, en nuestra sociedad como pertenecientes a miembros de clases sociales distintas. Querámoslo o no, estas variaciones nos ayudan a identificar socialmente a nuestra/o interlocutor, nos acercaremos, alejaremos, entablaremos contacto, rechazaremos su presencia o amistad, la discriminaremos o la aceptaremos, etc. Muriel Saville-Troitke en su libro Ethnography of Communication nos dice, en términos bien amplios, que realizar juicios acerca de la gente de acuerdo a sus rasgos lingüísticos es una forma común de estereotipar, lo cual es posible gracias a la naturaleza altamente visible de los marcadores en el lenguaje lo cuales están correlacionados con categorías extralingüísticas en una sociedad, tales como la raza, sexo, la edad, la clase social, la religión y la etnicidad. A su vez Mark Halliday nos dice que "el contexto interviene en la determinación de lo que decimos, y lo que decimos interviene en la determinación del contexto" (Halliday 1998, p.11), para él es difícil tener una impresión clara de lo que hacemos con el lenguaje en nuestra vida diaria, aun cuando el lenguaje es una parte importante de nuestra experiencia como seres humanos. Por ejemplo, creemos muchas veces no usar términos que discriminen, pensamos ingenuamente que son parte de la cultura a la cual pertenecemos, por lo tanto no son dañinos, me lo enseñó mi mamá, mi papá, mis abuelitos/tas, mis tíos y tías, creemos que no se nos enseñan cosas malas, como en el ingenuo juego que pregunta:

- ¿cuántos panes hay en el horno?

-21 quemados

- ¿quién los quemó? 
- el perro judío".

No sé si el juego aun se juega, al menos en mi época, en los años 70, sí se hacía. Pero ¿quién querrá terminar con los inocentes juegos de niños/as si son parte de nuestra cultura?

El sociolingüista inglés Ronald Wardhaugh señala que algunas investigaciones referidas a los idiomas muestran que hay de diferencias lingüísticas entre hombres y mujeres y que éstas están bastante esparcidas en el mundo, la pregunta interesante es por qué ésto es así. Wardhaugh señala algunas diferencias fonológicas en el habla de hombres y mujeres en diversas lenguas como el gros ventre, una lengua hablada en Noreste de EE.UU. Las mujeres pronuncian la palabra pan como kjatsa y los hombres como djatsa. Cuando estas mujeres citan a un hombre, ellas le atribuyen una pronunciación femenina al hombre citado, cuando un hombre cita a una mujer se le atribuye una pronunciación masculina a la mujer citada. Cualquier uso de una pronunciación femenina por parte de un hombre será vista como un acto de feminización de él. ¿Suena parecido a nuestra realidad? En bengalí los hombres a menudo sustituyen /// por el sonido inicial $/ \mathrm{n} /$, las mujeres, los niños y la gente sin educación no lo hacen. En la lengua siberiana chukchi, solamente los hombres no pronuncian los sonidos $/ \mathrm{n} / \mathrm{y} / \mathrm{t} /$ cuando ocurren entre vocales, por ejemplo una mujer pronunciaría la palabra nitvaqenat mientas un hombre nitvaqaat. En Montreal, más hombres que mujeres no pronuncian el sonido /// en los artículos del francés il, elle, la y le. En Escocia, las niñas estudiantes aparentemente prefieren pronunciar el sonido/t/ en palabras como water o got mientras que sus compañeros prefieren substituir ese sonido por el sonido glotálico /P/. En la lengua koasati, hablado en el suroeste de Louisiana, los hombres pronuncian un sonido /s/ al final de los verbos mientras que las mujeres no lo hacen, lakáws que quiere decir en castellano él lo está levantado es pronunciado por las mujeres lakáw. Por último, en esta larga cadena de ejemplos que nos tomaría una obra completa citar tal vez, en nuestra realidad lingüística del castellano de Chile, algunas mujeres tienden a pronunciar el sonido /s/ de la segunda persona singular tú, con mayor frecuencia que lo hombres, quienes omitimos aquel sonido, tú eres v/s tú ereh. En nuestro acento chileno, los hombres en su gran mayoría evitamos pronunciar las eses finales. Pues para algunos hablantes es un signo de pedantería o femineidad.

Ahora si nos movemos al tema de quien habla más, generalmente se señala que son las 
mujeres, pero estudios realizados entre mucho/as investigadores de las áreas de semántica y pragmática coinciden con la lingüista norteamericana Chris Kramer quien analizó tiras cómicas, tomadas de la revista New Yorker entre el 17 de febrero y el 12 de mayo de 1973. Sus investigaciones arrojaron que los hombres hablamos el doble que las mujeres y de temas distintos, tales como sobre negocios, política, asuntos legales, impuestos, deportes, entre otros, mientras que las mujeres lo hacen de vida social, libros, comidas y bebidas, problemas de la vida y estilos de vida.

Pero el lenguaje, ya sabemos, no es sólo palabras, en el pueblo ecuatoriano de Vilcabamba, donde viven los habitantes más longevos de aquel país, antes, se tocaban cinco campanadas si había fallecido un hombre y tres si se traba de una mujer. Las mujeres judías no usan kipá sí los hombres; las monjas y las mujeres católicas apostólicas romanas no pueden llegar a puestos altos dentro de la administración eclesial; algunas mujeres musulmanas cubren completamente su cuerpo no así los hombres.

Siempre podemos buscar explicaciones para uno u otro comportamiento, y hemos vivido por siglos con estas diferencias, sufriéndolas o imponiéndolas, rebelándose o acatándolas. ¿Cuántas mujeres importantes esconde la historia? En el mes de junio de 2010, el gobierno de Ecuador, presidido por Rafael Correa, envió los restos simbólicos de la genérala Manuela Sáenz que estuvo en el fragor de la lucha por la independencia de su país junto a Simón Bolívar, quien, actualmente, es considerada un ícono del feminismo en América Latina. El Presidente Chávez, citado por teleSUR el lunes 5 de julio de 2010 señaló que se hacía "un acto de justicia feminista", reivindicándola y reivindicando el papel histórico que ha desempeñado la mujer en las luchas revolucionarias. ¿Quién en nuestro país nos enseñó acerca de ella y de las grandes mujeres que han aportado a la libertad de nuestros pueblos? Más bien son las acompañantes de los grandes héroes.

Precisamente, volviendo a nuestro país, somos testigos de la invisibilización de las mujeres que ocupan puestos de poder en todo ámbito. Fuimos testigos hace algunos años del accionar político que sacó de su puesto a la entonces Ministra de Educación por una mayoría parlamentaria masculina, más allá de sus errores, pregunto ¿que ministro ha sido removido de su puesto en 
estos últimos 20 años de democracia por sus errores? Somos testigos del renovado debate por la postulación de Isabel Allende al Premio Nacional de Literatura, premio que han ganado sólo 3 mujeres hasta la fecha, a la que muchos escritores se niegan por variadas razones, todas de peso obviamente. Asimismo, somos testigos de la ultra-visibilización de las mujeres a través de la exhibición erótica de sus cuerpos, como en una carnicería, presa a presa, hormona a hormona, silicona a silicona, cumpliendo con el mandato de género de darnos placer a los hombres, cumpliendo, de alguna manera, con la división social del lenguaje de género, de las relaciones sociales a través de la gramática social imperante, de la cual habla la académica australiana Cate Poynton, cuando se refiere a la semiótica de las relaciones sociales, entendida ésta como el uso de ciertas palabras, sustantivos, adjetivos, entonación y estructuras sintácticas por parte de mujeres y hombres, además del poder, la fuerza, la autoridad, estatus que nos concede nuestro puesto en la sociedad. Por ejemplo, quien es profesor/a tiene la potestad de influir en al creación de imaginarios. Pero si desplazamos este concepto de gramática social podemos discriminar ciertos comportamientos personales, especialmente de aquellas personas que no se ajustan necesariamente a los comportamientos "míos" o "nuestros", como señalan Beatriz Preciado, Judith Butler y otras feministas la performance, las que deben de ir de acuerdo a los géneros a los cuales adscribamos: hetero, homo, trans, traves, o a la clase social, etnia, región de proveniencia, religión, etc, etc. Gilda Luongo, de la Corporación La Morada, en su artículo [en línea] Tonka-Tanka/ WakaWaka: los cuerpos del mundial ${ }^{3}$ publicado en el diario electrónico de la Radio de la Universidad de Chile, señala el sexismo y las actitudes de los medios de comunicación con respecto al Mundial de Fútbol Sudáfrica 2010 señalando quienes deberían ser lo supuestos seguidores de la selección de fútbol y quienes no "asimismo, pone en evidencia la misoginia más ácida cuando se señala: “QQuién dijo que a las mujeres no les importaba el fútbol? Hasta las menopáusicas despidieron a la roja" Una cultura que usa y abusa de sus mujeres, que se ríe burlonamente de los sujetos femeninos para resaltar al macho chileno futbolero muestra su hilacha autoritaria y descalificadora de las diferencias; sin embargo, en su ignorancia es capaz de disfrazarse de africanismo (así) de este modo olvida que la diferencia sexo-género es hermana de la diferencia racial y económica porque en el sistema sexo-género dominante cada una se trama inevitablemente con las otras" 4 
Como señala Teun van Dijk "el racismo se aprende y reproduce en gran medida a través del discurso dominante" (van Dijk 2007, p.26), puedo agregar con él que, además, la discriminación de género, la misoginia, la intolerancia también. Cómo ciudadano pregunto ¿tenemos acceso a modificar la pautas de programación, las líneas editoriales de canales de televisión, radios y medios escritos que usan y abusan de su poder para instalar temas en nuestra "agenda cultural"? A través de la palabra menopáusica se hace mofa pública de quienes están en aquella etapa biológica donde comienza la disminución por causas naturales de la producción estrógeno y progesterona, las hormonas que regulan el ciclo menstrual. Se podría entender que quienes profieren dichas expresiones tienen como objetivo ser "graciosos" y captar la atención o sintonía de los televidentes, pues el sistema de competencia televisiva requiere una buena audiencia para vender el espacio a más auspiciadores que son los que en definitiva hacen funcionar la máquina, y en la concreción de dicho objetivo, todos los recursos serían válidos aparentemente.

Por su parte, Saville-Troitke señala que "a differential distribution of language resources by sex in a community is often associated with differential patterns of education and distribution of labor, inlcuding trade versus childrearing responsabilities. Males are more likely to be educated, and thus to control the formal and written varieties of language. They are also more likely to be bilingual, both because of educational level, and because of mobility and contact in military encounters and trade" (Saville-Troike 1990, p.93). Como ejemplo de esto, la autora señala que las únicas personas monolingües de bereber en Argelia, es decir hablantes únicamente de esa lengua, son las mujeres. De misma manera, Cheris Kramarae (Kramarae 1981) señala que las mujeres perciben el mundo de manera diferente de los hombres porque las experiencias y actividades de hombres y mujeres están desarrolladas y fuertemente influidas por la división del trabajo. Las excepciones a este tipo de trato se dan en sociedades donde las mujeres tienen iguales oportunidades educativas y posibilidades de movilidad, en el caso de algunas etnias, donde no se dan matrimonios basados en alianzas. Saville-Troike señala el ejemplo de Guatemala donde las mujeres mayas tienen un rol básico relacionado con el comercio, su trabajo de venta en los mercados les permite ser bilingües, en castellano y su lengua maya nativa, o al menos entenderlo sin hablarlo, la cual puede ser Kich'e, Mam, Kaqchikel, Q'echì, entre las 22 existentes. Ofelia 
Ochirix, antropóloga de la Fundación de Antropología Forense de Guatemala (entrevista via correo electrónico) señala que hay algunas mujeres que hablan inglés, es decir son trilingües, especialmente aquellas que trabajan en la ciudad de Antigua, ciudad que recibe muchos turistas cada año. Otras mujeres hablan más de una lengua maya, lo que sumado al castellano, el inglés, y su propia lengua maya materna, da un total de 4 o 5 idiomas.

Retomando el caso de los resultados escolares reflejados en el SIMCE, sucede algo parecido, el hijo o hija de un empleado subcontratista recibe una educación distinta al hijo o hija de un empresario o de un académico, si bien hablamos una misma lengua, estamos en este caso refiriéndonos al manejo de los códigos exigidos en el sistema educativo, el cual es más elaborado que el registro coloquial, el cual, a su vez, es usado con nuestras amistades y enana gran cantidad de hogares de bajo nivel socio-económico.

El problema de las diferencias entre el uso del lenguaje por parte de hombres y mujeres no es tan importante creo, lo crucial es entender que esas diferencias no nos lleven a discriminar negativamente a las personas. Para ello requerimos una enseñanza integradora, abierta, democrática, plural y bastante profunda y contundente que no se limite a la escuela, la que enseña los contenidos fijados por el Estado solamente, sino que se dé en las familias y en los medios de comunicación. No bastan campañas en contra de la violencia en contra la mujer si ella es vista y reproducida todos los días como objeto de transacción, para vender, para deleitar a los clientes/consumidores de la sociedad del espectáculo. Se requiere de parte del Estado a través de su Ministerio de Educación, de las escuelas, las universidades que se enseñe, en el sentido amplio del concepto, que los usos que les damos a las palabras, expresiones, chistes, juegos, adivinanzas, metáforas, etc. están limitados por nuestras sociedades y culturas, de las que somos parte, en las que hemos nacido o hemos sido criados. Enseñar que lo que es verdad para $\mathrm{mi} /$ nosotros/nosotras/ellas/ellos no es necesariamente verdad o no es real para quien proviene de otra región del país o de algún país hispano-hablante, especialmente si habla otra lengua. 


\section{Conclusiones.}

Como conclusión, creo que un coloquio de esta envergadura, más allá de permitirnos aprender de quienes exponen, nos debe ayudar a ver nuestras propias realidades, a analizarnos, a extraer aquellas cosas que creemos ser capaces de poner en práctica en nuestras vidas para mejorar nuestras relaciones con el entorno social. Cambiar nuestras prácticas personales a veces es una tarea ardua, pero en algún momento debemos empezar. Creo que es útil dejar planteadas algunas sugerencias, como prometiera algunas líneas más arriba, las que han sido tomadas de la Comisión del Instituto de la Mujer de España. Dicha Comisión sugiere, entre una larga lista, cambiar el masculino pretendidamente genérico en los casos en que estén representados hombres y mujeres por sustantivos colectivos tales como persona, personal, equipo, público, pueblo, población, gente, etc.; o por sustantivos abstractos como profesorado, alumnado, estudiantado, vecindario, clientela, ciudadanía, electorado; o por metonimias como el cargo, la actividad, la profesión; o por el lugar, por ejemplo decir Cataluña en lugar de "los catalanes", Chile en vez de los chilenos, la Subdirección en lugar de "los subdirectores", la Presidencia, la Redacción (y no "los redactores"), las candidaturas (en vez de "los candidatos"), la infancia, la adolescencia, la clase periodística, la profesión médica; o en impresos, cuestionarios, ofertas de empleo y ciertos documentos, como un convenio laboral en el que aparece una lista del personal afectado por el mismo, se puede recurrir incluso a la arroba, siempre que se trate de textos no destinados a ser leídos en voz alta. Pueden haber cambios en la redacción de las oraciones, en lugar de la frase "Durante diez días los compradores tienen opción a la devolución de su dinero", se puede cambiar la redacción a frases como: "Durante diez días se tiene opción a la devolución de su dinero" o "Durante diez días después de la compra existe opción a la devolución de su dinero."

Señala la Comisión que son asimismo sexuados muchos adjetivos que poseen formas masculina y femenina (emprendedora, listo). Para no utilizar las formas masculinas como genéricas se puede sustituir el adjetivo de doble forma (lista, listo) por un adjetivo sinónimo invariable para el género inteligente, emprendedor, emprendedora por audaz; o sustituir el adjetivo por un sustantivo 
de la misma familia léxica que el adjetivo o un sinónimo, o por una preposición y un sustantivo de la misma familia léxica que el adjetivo o por un sinónimo de aquél. Por ejemplo, "son muy listos" por "tienen gran inteligencia"; "los más votados" por "quienes hayan obtenido mayor número de votos"; "nadie está más convencido" por "nadie tiene más convencimiento." Si bien la lista es bastante larga , quiero terminarla con algo que me parece bastante útil. La Comisión sugiere que se puede optar por hacer concordar los artículos, determinantes, adjetivos o participios únicamente con el más próximo. Es un criterio aceptado por la norma académica y frecuentemente utilizado: "mi casa tiene techos, paredes y puertas blancas" es una frase que "suena" perfectamente válida y normal, mientras que nos parecería extraño "mi casa tiene techos, paredes y puertas blancos". Por ello, se puede acudir al criterio de concordancia de proximidad como una forma de evitar la concatenación de formas femeninas y masculinas. Si se alterna el orden del masculino y el femenino, el texto adquiere dinamismo y se concede al orden de aparición un sentido puramente aleatorio, en lugar de jerárquico, como ahora, cuando en todo tipo de texto se nombra antes lo masculino ("hijos e hijas", "padre y madre", "niños y niñas..."): "Los delegados y delegadas presentes en la reunión" "Las delegadas y delegados salientes recibieron una ovación".

Pero no basta sólo con los cambios en los usos lingüísticos, cuando empecemos a ver al hijo e hija del subcontratado y la subcontratada igual que a la hija o al hijo del empresario o la empresaria, cuando las hijas y los hijos de la nana sean iguales a los de las académicas o los académicos y del inmigrante o la inmigrante, tal vez empecemos a cimentar las bases de un futuro y esperado cambio social, de la gramática social. 


\section{Bibliografía}

BERSTEIN, B. La Estructura del Discurso Pedagógico. Clases, códigos y control (volumen IV). $4^{a}$ edición. Madrid. Ediciones Morata, S. L. 2001.

HALLIDAY, M. El lenguaje como Semiótica Social. La interpretación social del lenguaje y del significado.1aㅡ edición. Colombia. Fondo de Cultura Económica, 1998.

HYMES, Dell. Foundations in Sociolinguistics. An ethnographic approach. $1^{\underline{a}}$ edition. UK. Tavistock Publications. 1977.

GUMPERZ, J. J. y A. BENNETT. Lenguaje y Cultura. Barcelona. Editorial Anagrama. 1981.

MILLS, S. (editor). Language and Gender: Interdisciplinary perspectives. USA. Longman Publishing. 1995.

POYNTON, C. Language and Gender: Making the Difference. Hong Kong. Oxford University Press. 1990.

SAVILLE-TROIKE, Muriel. The Ethnography of Communication. An Introduction. Second edition. Basil Blackwell. UK. 1990.

VAN DIJK, T. (Coord.) Racismo y Discurso en América Latina. 1aㅡ edición. Barcelona. Gedisa Editorial. 2007.

WARDHAUGH, R. An introduction to Sociolinguistics. 1를 edition. UK. Basil Blackwell. 1987. 
Linkografía:

INSTITUTO DE LA MUJER, SECRETARIA GENERAL DE POLITICAS DE SEXUALIDAD, $\begin{array}{lllll}\text { MINISTERIO } & \text { DE } & \text { IGUALDAD } & \text { [en }\end{array}$ http://www.inmujer.migualdad.es/mujer/publicaciones/catalogo/serie lenguaje.htm [consulta: 2 julio de 2010].

[en línea] http://lapenalinguistica.blogspot.com [consulta: 2 julio de 2010].

LUONGO, G. [en línea] Tonka-Tanka/ Waka-Waka: los cuerpos del mundial http://radio.uchile.cl/opiniones/70802 [consulta: 2 julio de 2010]

[en línea] http://www.rae.es [consulta: 2 de julio 2010]

[en línea] Metodología de Construcción de Grupos Socioeconómicos en SIMCE 2009 4ํㅡásico 2009. Junio 2010. http://www.simce.cl/ [consulta: 2 julio de 2010]

[en línea] Metodología de Construcción de Grupos Socioeconómicos en SIMCE 2009 8 Básico 2009. Junio 2010. http://www.simce.cl// [consulta: 2 julio de 2010]

[en línea] http://600.mineduc.cl/docs/informacion/info guia/guia enla.pdf [consulta: 2 julio de 2010]

[en línea] Kramarae, Ch. (Cheris Kramer). "Folk Linguistics: Wishy-Washy Mommy Talk." Psychology Today 8 (June 1974): 83-85. http://course1.winona.edu/pjohnson/gender/kramer1.htm [consulta: 2 julio de 2010] 
${ }^{1}$ Ver http://lapenalinguistica.blogspot.com [consulta: 20 julio de 2010].
${ }^{2}$ Ver www.enlaces.cl [consulta: 3 julio de 2010].
${ }^{3}$ Ver http://radio.uchile.cl/opiniones/70802 [consulta: 12 julio de 2010],
${ }^{4}$ Ver http://radio.uchile.cl/opiniones/70802 [consulta: 20 noviembre de 2010]. 